MABR

6,3

280

Received 1 November 2020

Revised 13 March 2021

23 March 2021

23 May 2021

24 May 2021

Accepted 24 May 2021

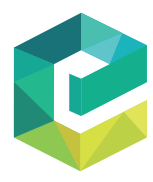

Maritime Business Review Vol. 6 No. 3, 2021 pp. $280-292$

Emerald Publishing Limited $2397-3757$

DOI 10.1108/MABR-11-2020-0066

\section{An empirical study of the performance of weather routing service in the North Pacific Ocean}

\author{
Chaur-Luh Tsai, Dong-Taur Su and Chun-Pong Wong \\ Department of Shipping Technology, \\ National Kaohsiung University of Science and Technology, \\ Kaohsiung, Taiwan, R.O.C
}

\begin{abstract}
Purpose - The objective of this research is to examine the performance of weather routing service in the North Pacific Ocean based on a global container shipping company.

Design/methodology/approach - The data comprise two passages: one that departs from the port of Taipei to the port of Los Angeles (TPE-LAX) and another that departs from the port of Tacoma to the port of Kaohsiung (TCM-KSG). A weather routing service was utilized to compare the differences of the distance, sailing time and fuel consumed among different voyages.

Findings - Results indicated that the average speed of vessel in winter is faster than in summer. The vessels consumed much more fuel in the winter than they did in the summer. In terms of the distance of the passage, the results show that the ships' sailing distance across the North Pacific Ocean in the summer was shorter than it was in the winter.

Research limitations/implications - Due to the difficultly of practical data collection, relatively few sailing records were employed in this study. It is suggested that additional sailing records should be collected, which adopt weather routing recommendations, to more comprehensively analyze sailing performance in future research.

Practical implications - The study's findings offer valuable guidance to different stakeholders in the maritime industry (e.g. seafarers, marine hull and machinery companies, Protection and Indemnity Club (P\&I), ocean container carriers and freight forwarders) to clarify their responsibilities in order to achieve desired sailing outcomes.

Originality/value - To the best of the authors' knowledge, the current study is the first research to utilize practical sailing data to provide objective evidence of sailing performance based on a weather routing service, which can assist various stakeholders to make optimal decisions.
\end{abstract}

Keywords Sailing, Ocean route, Weather, North Pacific Ocean

Paper type Research paper

\section{Introduction}

Global seaborne trade supports global economic development. In 2019, there were 98,140 global-shipping merchant vessels that carried a total of 11.08 billion tons of cargo (UNCTAD, 2020). The majority of such vessels sail in the three main east- and west-bound trade lanes, and a minority sail in the south and north subtrade lanes. The three main trade passages transit the Atlantic Ocean, the Pacific Ocean and the Indian Ocean. An evident question is how can vessels sail safely and economically in complicated seas, and especially across oceans?

Conventionally, ships' navigators apply special nautical skills, basic equipment and certain maritime publications, e.g., Planning Guides, the Sailing Directions, the Distance Table between Ports of the World and the seasonal Pilot chart, to find desired route (NIMA, 2002; NGIA, 2018a). After selecting a recommended route, together with information on

\footnotetext{
(C) Pacific Star Group Education Foundation. Licensed re-use rights only.

The study thanks for Mr. Zhi-Ming Lu, whom provides the data of sailing and describes the interesting experience during the period onboard, which encourage us to complete the research.
} 
currents and meteorology for specific ocean areas, navigators can identify the shortest, safest and most comfortable route to complete a voyage.

In addition to the above-mentioned sailing information, navigators also employ sailing planning techniques to select optimal routes. The primary sailing methods are great circle (GC) and rhumb line (RL) sailing. These two methods possess corresponding advantages and disadvantages. Specifically, GC sailing can achieve a shorter distance; whereas, it has a greater probability to confront colder weather, stronger winds, higher seas and even icebergs because it reaches higher latitudes close to the poles. The advantage of RL sailing, on the other hand, is that it is easy to plan and sail with simple nautical equipment and navigating charts; however, it needs to sail a longer distance compared with the GC sailing route.

Irrespective of whether the navigator sails in GC or RL mode, they all sail in uncertain weather conditions. Indeed, they must frequently adjust the ship's course and speed, as well as change routes according to any contingencies that they may encounter. It is also possible that navigators may be unable to accurately determine a voyage's risk, and a voyage may become uneconomical and constitute a financial loss. Extant literature (Brodl, 2017; Chen, 2002; Chen and Lee, 2008; Flecks, 2009; Lu, 2014; Tsou and Cheng, 2013; Wang and Jia, 1998; Wei and Zhou, 2012) has demonstrated that the efficiency of transoceanic ship route planning is generally determined by the accuracy of the prediction of the ship's hydrodynamic behavior under different weather conditions, the accuracy of the weather forecast and the capability and practicability of optimization algorithms. In our modern era, weather routing services are applied as a major supportive tool to improve sailing performance. Weather routing services provide weather forecasts that the navigator uses to understand weather that may affect the voyage (NGIA, 2018a; NIMA, 2002) to enhance sailing performance. In fact, utilization of weather routing services is becoming increasingly common in ocean transit (Tsou and Cheng, 2013). These services aim to provide marine weather forecasts and to recommend optimal ship routes for sea passage. However, to the best of the authors' knowledge, there is a paucity of literature that broadly examines the performance of ships that employ weather routing services in ocean transit. To bridge this research gap, this study attempts to elucidate the empirical performance of weather routing and its influence on stakeholders in the shipping industry.

The remainder of this paper proceeds as follows. The second section presents a review of the pertinent literature. The third section describes the methodology applied in this study and the fourth section provides the results of data analysis. Finally, the discussions and conclusions of this study, as well as suggestions for future research, are given in section five.

\section{Literature review}

Navigation safety constitutes the mariners' primary responsibility. Indeed, ensuring the ship's safety always takes precedence over completing operational commitments and carrying out the ship's routing service. Prior to the beginning of each voyage, the navigator must develop a detailed sailing plan that delineates precisely how the entire voyage is to proceed sequentially, which includes charting courses, forecasting the weather and tides, checking the Sailing Directions and the Coast Pilots and projecting future events that may be encountered during the voyage (NGIA, 2018a, p. 437). Such publications can provide climatic data, such as wind speed and direction, wave height frequencies and ice limits, for the major ocean basins of the world. In fact, the Planning Guides greatly assist the navigator in planning an extensive oceanic voyage, by providing useful information about all of the countries adjacent to a particular ocean basin (NIMA, 2002). They may also recommend specific routes based on various weather conditions.

Generally, when a vessel is planning an ocean transit, the navigator checks all of the information provided in the Pilot Chart to create a sailing plan. The Pilot Chart depicts the 
MABR

6,3

average conditions in terms of prevailing winds and currents, air and sea temperatures, wave heights, ice limits, visibility, barometric pressure and weather in different seasons of the year. The information used to compile these averages was obtained from oceanographic and meteorological observations at sea over many decades (NIMA, 2002; NGIA, 2018a). Since it is so comprehensive, it constitutes the first resource for route planning regarding weather conditions. In addition to the Pilot Chart and other resources, the navigator plans the voyage transit by various sailing methods.

The navigator applies two primary sailings techniques, GC and RL, to design his or her sailing plan. GC is an especially prominent technique for commercial vessels transiting across the Atlantic Ocean and the Pacific Ocean. The major advantage of GC sailing is that it is able to achieve a markedly shorter travel distance (NIMA, 2002; NGIA, 2018a). Its disadvantages, depending on latitude, could be colder weather, stronger winds, higher seas and even icebergs (NGIA, 2018b). The RL technique, however, has constant bearings and crosses all meridians at the same angle and thus is able to maintain the same angle with respect to true north. For example, an RL on a Mercator projection is a straight line. As a consequence, navigators can follow a single compass bearing to develop his or her sailing plan along a straight line. It is also worth noting that when traveling over a short distance along an RL, it may seem that is traveling in a straight line; however, the path is actually a curve, and if the sailing distance is extended, it eventually proceeds into a spiral toward the North or South Pole. Although the RL appears as if it achieves the shortest distance in certain map projections, in fact it does not when traveling long distances on a sphere, such as the Earth. Regardless of whether the navigators apply GC or RL, distance is just one of numerous practical factors involved in determining the sailing plan. In terms of operation performance and safety, for example, weather is likely to be the decisive factor in most cases (Chen, 2002; Chen and Lee, 2008).

The prediction of weather at some future point in time is based on an understanding of weather processes and observations of present conditions. The factors used to determine weather conditions are many and varied. Continual advancements in knowledge of weather has enabled increasingly accurate weather predictions. It is also worth noting that the ability to forecast is acquired through study and long practice (NIMA, 2002). In other words, if a navigator can correctly interpret observations made from his or her own vessel, he or she may be able to predict the weather for the next several hours much more reliably than a trained meteorologist who is ashore. Of course, prediction of weather conditions for several hours is markedly insufficient for a long trip across the ocean. Indeed, more information and support from a pertinent, accurate and comprehensive database is needed.

In recent decades, ship weather routing has become an invaluable tool to support navigators to transit the ocean safely. Routing agencies develop an optimum track for ocean voyages based on forecasts of weather and sea conditions (She and Lin, 2011), as well as a ship's individual specifications for a particular transit (Lu, 2014; Su, 1999; Tsou and Cheng, 2013). Within specified limits of weather and sea conditions, it is then possible to maximize safety and crew comfort, minimize fuel consumption and time required and a desired combination of these factors. The ship routing agency, acting as an advisory service, attempts to avoid or reduce the effects of specific adverse weather and sea conditions by issuing initial route recommendations prior to sailing. It also recommends track changes while underway (diversions) and weather advisories to alert the ship's navigator about approaching unfavorable weather and sea conditions, which cannot be effectively avoided by a diversion.

Several private meteorological groups implemented the concept of ship weather routing in the 1950s (NIMA, 2002). Currently, some private firms provide routing services to shipping industry clients. Moreover, several computer-based software applications have become available and popular, making weather routing available to virtually everyone at sea. The ship's captain can thus easily evaluate various scenarios, select routes and display track data 
onboard. Moreover, weather routing services are no longer only for safe sailing, but have become an important management tool of stakeholders in the shipping industry, such as ship operators, insurance companies, shippers and charterers. However, there is a lack of empirical research that has investigated the influence of weather routing services on sailing performance. As a consequence, this study aims to bridge this research gap and determine optimal ways of employing weather routing services.

\section{Weather routing service}

\section{Methodology}

The current study attempts to elucidate the significance of sailing plans that apply weather routing services at a practical level. Regarding sailing, navigators have long applied basic knowledge derived from traditional experience to achieve various levels of performance. Currently, however, some new technologies employed in modern sailing exist, and weather routing services are prominent among them. Due to the breadth of complex phenomena that can occur at sea and the limitation of quantitative data collection, the study extended its scope beyond the quantitative statistical method (Zainal, 2007). According to research logic that focuses on stipulation and operationalization of complex chains of occurrences or events over an extended period of time, Yin (2014) recommends that studies use an empirical inquiry to investigate a contemporary phenomenon in depth and within its real-world context. The current investigation examines sailing records across the Pacific Ocean to discover the performance of ocean routes, and the six-element procedures of the case study, e.g. plan, design, preparation, data collection, analysis and reporting (Yin, 2014), were employed.

The data applied in the current study are the sailing records of a fleet in a container shipping company that is ranked in the top four globally, which transits across the North Pacific Ocean and utilizes a weather routing service. The fleet consists of the same type of ships, and it has encountered similar sailing conditions (Su, 1999). The sailing data are distributed in each month of the entire year. The data comprise two passages: one that departs from the port of Taipei to the port of Los Angeles (TPE-LAX) and another that departs from the port of Tacoma to the port of Kaohsiung (TCM-KSG). Because passage across the Pacific Ocean is a popular route, a basic conventional route has long been established. The study compared the collected data with this conventional route to elucidate the relationship between the distance, sailing time and fuel consumed among different voyages. In addition, certain voyages were selected for more detailed discussions in the current study if any weather variations occurred during the voyages.

\section{Data analysis}

\subsection{Conventional ocean passage across the North Pacific Ocean}

As previously stated, a sailing plan to cross the North Pacific Ocean normally has two major options: GC sailing and RL sailing. Table 1 presents the data of the conventional oceanic passage by GC and RL sailing across the North Pacific Ocean. Table 1 shows that the distance

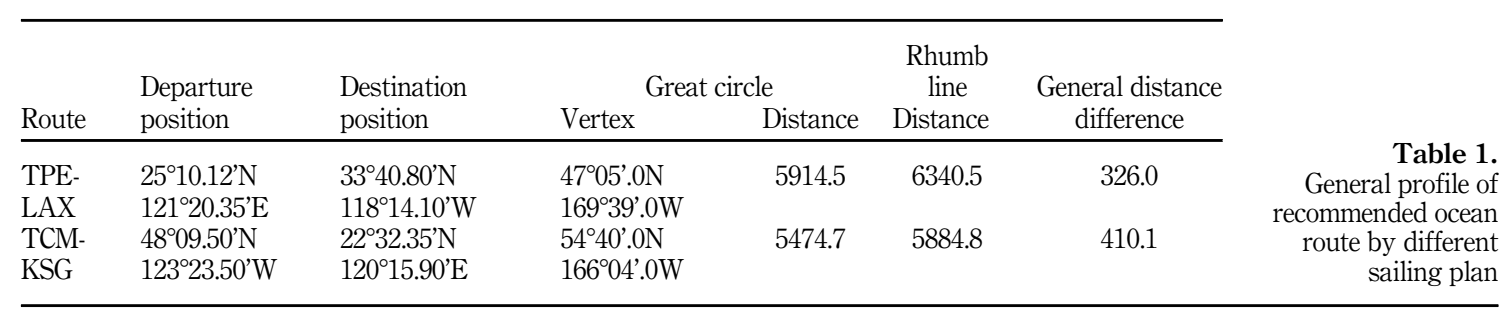


MABR

6,3

\section{4}

Figure 1.

General tracks of GC and RL from TPE to LAX on the Mercator chart

Figure 2.

General tracks of GC and RL from TCM to KSG on the Mercator chart of the route of TPE-LAX is 5914.5 nautical miles (n.m.) with the vertex at latitude $47^{\circ} 05^{\prime} .0 \mathrm{~N}$ and longitude $169^{\circ} 39^{\prime} .0 \mathrm{~W}$ when in $\mathrm{GC}$ sailing; whereas the distance is $6340.5 \mathrm{n}$.m. when in RL sailing. Regarding the route of TCM-KSG, its distance is 5474.7 n.m. with the vertex at latitude $54^{\circ} 40^{\prime} .0 \mathrm{~N}$ and longitude $166^{\circ} 04^{\prime} .0 \mathrm{~W}$ via north of the Aleutian Islands, transiting through the Tsu-garu Strait and the Tsu-shima Strait when in GC sailing; whereas when in $\mathrm{RL}$ sailing, the distance is $5884.8 \mathrm{n} . \mathrm{m}$. The distance difference of these routes employing GC and RL sailings is 326.0 n.m. of TPE-LAX and 410.1 n.m. of TCM-KSG, respectively.

The tracks of both GC and RL sailings are shown in Figure 1 and Figure 2 on the Mercator chart, respectively. Due to chart distortion, the RL appears as a straight line that connects the points, while the GC appears as a sine curve which is convex to the pole on the Mercator chart.

\subsection{Profile of sailing records}

The data employed in the current research are recent sailing records of a fleet transiting the North Pacific Ocean during the end of a year through the end of the subsequent year. Table 2
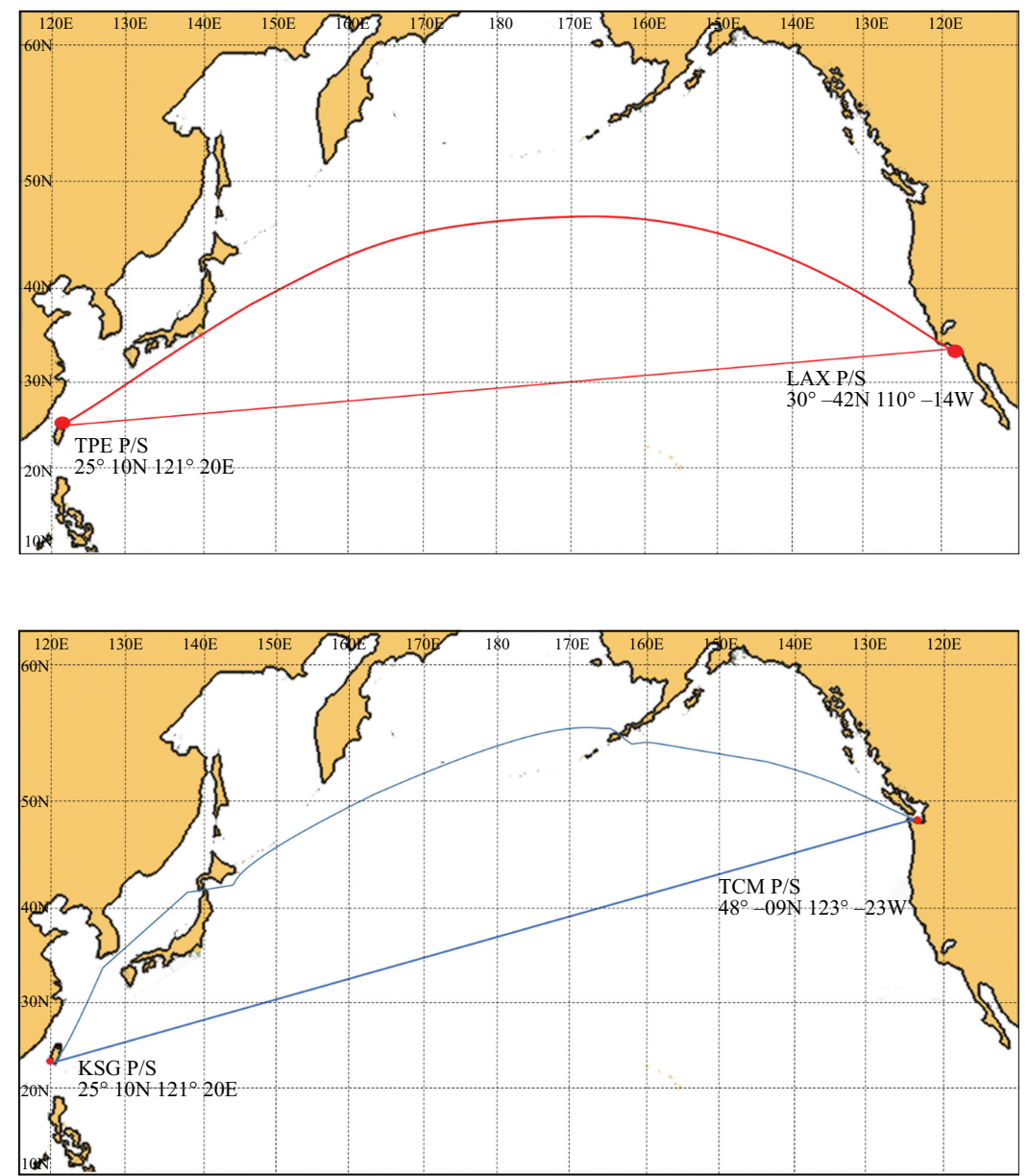


\begin{tabular}{|c|c|c|c|c|c|c|c|c|}
\hline & No. & $\begin{array}{c}\text { Departure } \\
\text { date }\end{array}$ & $\begin{array}{l}\text { Latitude of } \\
\text { vertex }\end{array}$ & Distance & $\begin{array}{l}\text { Average } \\
\text { speed }\end{array}$ & $\begin{array}{c}\text { Running } \\
\text { hours }\end{array}$ & $\begin{array}{c}\text { Fuel } \\
\text { consumption }\end{array}$ & $\begin{array}{l}\text { Weather } \\
\text { routing service }\end{array}$ \\
\hline $\begin{array}{l}\text { Eastbound } \\
\text { (TPE- LAX } \\
\text { route) }\end{array}$ & $\begin{array}{l}\text { E1 } \\
\text { E2 } \\
\text { E3 } \\
\text { E4 } \\
\text { E5 } \\
\text { E6 } \\
\text { E7 } \\
\text { E8 } \\
\text { E9 } \\
\text { E10 } \\
\text { W1 } \\
\text { W2 } \\
\text { W3 } \\
\text { W4 } \\
\text { W5 } \\
\text { W6 } \\
\text { W7 } \\
\text { W8 } \\
\text { W9 } \\
\text { W10 }\end{array}$ & $\begin{array}{l}15 / 12 \\
21 / 12 \\
22 / 02 \\
28 / 03 \\
04 / 07 \\
11 / 07 \\
25 / 07 \\
12 / 09 \\
19 / 09 \\
28 / 12 \\
\text { Average } \\
03 / 01 \\
09 / 01 \\
13 / 03 \\
18 / 04 \\
25 / 07 \\
01 / 08 \\
15 / 08 \\
04 / 10 \\
10 / 10 \\
17 / 01 \\
\text { Average }\end{array}$ & $\begin{array}{l}40^{\circ} 00^{\prime} .1 \mathrm{~N} \\
37^{\circ} 41^{\prime} .7 \mathrm{~N} \\
40^{\circ} 06^{\prime} .3 \mathrm{~N} \\
44^{\circ} 50^{\prime} .3 \mathrm{~N} \\
45^{\circ} 46^{\prime} .5 \mathrm{~N} \\
45^{\circ} 27^{\prime} .6 \mathrm{~N} \\
46^{\circ} 27^{\prime} .0 \mathrm{~N} \\
45^{\circ} 5^{\prime} .3 \mathrm{~N} \\
44^{\circ} 4^{\prime} .0 \mathrm{~N} \\
47^{\circ} 13^{\prime} .7 \mathrm{~N} \\
\\
56^{\circ} 48^{\prime} .7 \mathrm{~N} \\
54^{\circ} 2^{\prime} 1.6 \mathrm{~N} \\
54^{\circ} 34^{\prime} .7 \mathrm{~N} \\
54^{\circ} 07^{\prime} .9 \mathrm{~N} \\
54^{\circ} 21^{\prime} .0 \mathrm{~N} \\
54^{\circ} 16^{\prime} .2 \mathrm{~N} \\
54^{\circ} 09^{\prime} .2 \mathrm{~N} \\
54^{\circ} 28^{\prime} .9 \mathrm{~N} \\
54^{\circ} 09^{\prime} .0 \mathrm{~N} \\
54^{\circ} 28^{\prime} .2 \mathrm{~N}\end{array}$ & $\begin{array}{l}6036.4 \\
6156.4 \\
6073.9 \\
5970.3 \\
5972.2 \\
5975.9 \\
5975.1 \\
5930.8 \\
6028.0 \\
5915.6 \\
6003.5 \\
5657.9 \\
5481.9 \\
5562.9 \\
5512.2 \\
5659.3 \\
5562.2 \\
5664.0 \\
5616.3 \\
5578.3 \\
5558.7 \\
5585.4\end{array}$ & $\begin{array}{l}21.33 \\
19.93 \\
19.83 \\
18.01 \\
18.71 \\
18.45 \\
18.03 \\
18.39 \\
18.21 \\
19.53 \\
19.04 \\
16.94 \\
16.09 \\
16.05 \\
16.79 \\
16.38 \\
16.84 \\
16.47 \\
17.79 \\
16.33 \\
17.02 \\
16.67\end{array}$ & $\begin{array}{l}283.0 \\
308.9 \\
306.3 \\
331.5 \\
319.2 \\
323.9 \\
331.4 \\
322.5 \\
331.0 \\
302.9 \\
316.1 \\
334.0 \\
340.7 \\
346.6 \\
328.3 \\
345.5 \\
330.3 \\
343.9 \\
315.7 \\
341.6 \\
326.6 \\
335.3\end{array}$ & $\begin{array}{l}1639.0 \\
1553.2 \\
1390.7 \\
1228.0 \\
1183.3 \\
1149.2 \\
1141.6 \\
1238.6 \\
1364.3 \\
1553.0 \\
1344.1 \\
1275.4 \\
1181.1 \\
1094.4 \\
1109.4 \\
1189.8 \\
1035.8 \\
1119.9 \\
1228.3 \\
1235.8 \\
1129.7 \\
1160.0\end{array}$ & $\begin{array}{r}\text { Table } 2 . \\
\text { Sailing record in which } \\
\text { a weather routing } \\
\text { service was utilized }\end{array}$ \\
\hline
\end{tabular}

displays the record of the eastbound route of TPE-LAX and the westbound route of TCMKSG. It comprises ten voyages of each route that were sailed by GC sailing with a weather routing service. Various sailing results were achieved in different seasons during the year. Concerning the eastbound route, the average distance was 6,003.5 n.m., the average sailing time was 316.1 hours and consumed fuel was 1,344.1 metric tons $(\mathrm{m} / \mathrm{t})$ per voyage. Furthermore, the longest distance was $6,156.4$ n.m. in voyage E2 with the vertex at $37^{\circ} 41^{\prime} .7 \mathrm{~N}$; whereas the shortest distance was $5,915.6 \mathrm{n} . \mathrm{m}$. in voyage E10 with the vertex at $47^{\circ} 13^{\prime} .7 \mathrm{~N}$. The results showed that shorter distances were attained when sailing by GC with a higher latitude route. The longest sailing time took 331.5 hours to reach the destination with total consumed fuel of $1,228 \mathrm{~m} / \mathrm{t}$ in voyage E4; the shortest sailing time was 283 hours with total consumed fuel of $1,639 \mathrm{~m} / \mathrm{t}$ in voyage $\mathrm{E} 1$.

In terms of the westbound sailing records between the ports of Tacoma and Kaohsiung, the fleet followed the general ocean route via north of the Aleutian Islands and the straits of Tsu-garu and Tsu-shima to the port of Kaohsiung in Taiwan. Because the weather in these areas is relatively gentle, even though it is located at as high of a latitude as $50^{\circ} \mathrm{N}$, the navigator can achieve a shorter sailing distance. The average recorded distance of this route between the port of Tacoma and the port of Kaohsiung was 5,585.4 n.m., the average sailing time was 335.3 hours and the total consumed fuel was $1,160.0 \mathrm{~m} / \mathrm{t}$ per voyage. The data presented in Table 2 indicate that the shortest distance was 5,481.9 n.m., while the longest distance was $5,657.9$ n.m. This distance difference of 176.0 n.m. is evidently substantial. The shortest running time was 315.7 hours, which occurred in voyage W8 in the early winter; whereas the longest running time was 346.6 hours, which occurred in voyage W3. The difference of maximum and minimum sailing time was 30.9 hours. Regarding fuel consumption, the smallest quantity was $1,035.8 \mathrm{~m} / \mathrm{t}$ in voyage $\mathrm{W} 6$ in the summer, while the largest quantity was $1,275.4 \mathrm{~m} / \mathrm{t}$ in voyage $\mathrm{W} 1$ in the winter. The difference of fuel oil consumption was $239.6 \mathrm{~m} / \mathrm{t}$. 
MABR

6,3

\section{6}

Table 3.

Comparisons of the records of selected voyages and the average data of summer and winter

\subsection{Comparisons of the outstanding records of sailing}

4.3.1 Analysis of the sailing records of the eastbound route. In this section, the study examines significant differences in the records of certain selected voyages, e.g. E1, E2, E5 and W9, concerning the averages of summer and winter GC sailing. Table 3 presents the average data in summer (June to August) and winter (December to February) and the differences of the selected voyages compared with them.

The results indicate that the distance of voyage $\mathrm{E} 1$ was $62.0 \mathrm{n} . \mathrm{m}$. longer than the average in summer and $0.3 \mathrm{n.m}$. longer than the average in winter. In terms of speed, the average speed in E1 was 21.33 knots, which was 2.93 knots faster than the average speed in summer and 1.07 knots faster than the average speed in winter. Fuel consumption was 481.0 tons more than the average consumption in summer and $57.3 \mathrm{~m} / \mathrm{t}$ more than the average consumption in winter. However, travel time was 41.8 hours shorter than the average time spent in summer and 15.3 hours shorter than the average time spent in winter. These results show that the vessels consumed more fuel when they sailed longer distances and traveled at faster speeds.

Table 3 also displays the differences of voyage E5 compared with the average of summer and winter. The results show that the distance was 63.9 n.m. shorter than the average in winter and 2.2 n.m. less than the average in summer. Regarding speed, the average speed in voyage E5 was 18.71 knots, which was 1.55 knots slower than the average speed in winter and 0.31 knots faster than the average speed in summer. Fuel consumption was $398.4 \mathrm{~m} / \mathrm{t}$ less than the average consumption in winter, while fuel consumption was $25.3 \mathrm{~m} / \mathrm{t}$ more than the average in summer. However, travel time was 20.9 hours longer than the average time spent in winter, while it was 5.6 hours shorter than the average time spent in summer. These results demonstrate that the vessels consumed much more fuel in the winter than they did in the summer. In terms of the distance of the passage, the results show that the ships' sailing distance across the North Pacific Ocean in the summer was shorter than it was in the winter. In fact, the passage in the summer can generally be designed with a vertex of a higher latitude than that in the winter due to the frequent occurrence of violent weather events (Chang, 2012; Chen, 2002; Chen and Lee, 2008).

Table 3 shows that the distance of the winter voyage $\mathrm{E} 1$ was longer than the averages of winter and summer, and as much as $398.4 \mathrm{~m} / \mathrm{t}$ more fuel was consumed compared to that in winter. The summer voyage E5 had a shorter distance than it had on average in the winter and summer and consumed less fuel, as well. The records also reveal that the voyage E5 consumed as much as $398.4 \mathrm{~m} / \mathrm{t}$ less fuel in winter, but consumed $25.3 \mathrm{~m} / \mathrm{t}$ more fuel in summer. The results provide strong evidence that sailing in the summer is more economical than that in the winter.

\begin{tabular}{lrccc}
\hline Average data/Difference & Distance & Avg. Speed & Sailing hours & Fuel consumption \\
\hline Average of winter data of eastbound (WE) & 6036.1 & 20.26 & 298.3 & 1581.7 \\
Average of summer data of eastbound (SE) & 5974.4 & 18.40 & 324.8 & 1158.0 \\
Average of summer data of westbound (SW) & 5628.5 & 16.56 & 339.9 & 1115.2 \\
Average of winter data of westbound (WW) & 5566.2 & 16.68 & 333.8 & 1195.4 \\
Difference (E1-WE) & +0.3 & +1.07 & -15.3 & +57.3 \\
Difference (E2-WE) & +120.3 & -0.3 & +10.6 & -28.5 \\
Difference (E5-WE) & -63.9 & -1.55 & +20.9 & -398.4 \\
Difference (E1-SE) & +62.0 & +2.93 & -41.8 & +481.0 \\
Difference (E2-SE) & +182.0 & +1.5 & -15.9 & +395.2 \\
Difference (E5-SE) & -2.2 & +0.31 & -5.6 & +25.3 \\
Difference (W9-SW) & -50.2 & -0.23 & +1.7 & +120.6 \\
Difference (W9-WW) & +12.1 & -0.35 & +7.8 & +40.4 \\
& & & &
\end{tabular}


The selected voyages of E1 and E2 were all across the North Pacific Ocean by GC sailing from the port of Taipei to the port of Los Angeles in winter. The voyage E1 reached the vertex at a higher latitude of $40^{\circ} 00^{\prime} .1 \mathrm{~N}$ and traveled a shorter distance; whereas the vertex of voyage $\mathrm{E} 2$ was as low as $37^{\circ} 41^{\prime} .7 \mathrm{~N}$ with a distance $120.3 \mathrm{n} . \mathrm{m}$. longer than the winter average. However, the fuel consumption of voyage E1 was significantly increased by $57.3 \mathrm{~m} / \mathrm{t}$ compared with the winter average, while voyage E2 was less by $28.5 \mathrm{~m} / \mathrm{t}$. These results illustrate that the performance of sailing across the North Pacific Ocean was characterized by fluctuation. Therefore, navigators should not focus only on shortening the sailing distance but also consider multiple contingencies, such as meteorological conditions, ocean currents, speed, sailing time, fuel consumption, cargo safety, etc. when they accept the recommendations of weather routing services or make sailing decisions by themselves.

4.3.2 Analysis of the sailing records of the westbound route. Table 3 displays the comparison results of voyage $\mathrm{W} 9$, as well as the average data. The results show that the distance was 50.2 n.m. shorter than the average in summer, while it was 12.1 n.m. greater than the average in winter. Concerning speed, the average speed in voyage W9 was 16.33 knots, which was 0.35 knots slower in winter and slower 0.23 knots in summer. Fuel consumption was $40.4 \mathrm{~m} / \mathrm{t}$ greater than the average consumption in winter and $120.6 \mathrm{~m} / \mathrm{t}$ greater than the average consumption in summer. Moreover, travel time was 7.8 hours longer than average travel time in winter and 1.7 hours longer than the average travel time in summer. The fuel consumption of the passage of voyage W9 was greater than the average consumption both in summer and in winter. This particular finding might be attributable to encountering a severe weather condition during the sailing period. The results indicate that vessels might not always gain economic benefits if they sail in accordance with the suggestions of weather routing services.

Generally, the westbound route from the port of Tacoma to the port of Kaohsiung transits via north of the Aleutian Islands and the straits of Tsu-garu and Tsu-shima. It is difficult to verify the efficiency of the weather routing service according to the data. The study selected a remarkable record of voyage $\mathrm{W} 9$, which spent 341.6 hours sailing $5,578.3$ n.m. and consumed $1,235.8 \mathrm{~m} / \mathrm{t}$ of fuel. There was no obvious difference identified by these data compared with the other records. The sailing track is presented on a chart in Figure 3. As the figure shows, the vessel deviated from the passage to the south at approximately longitude $165^{\circ} \mathrm{E}$ and then changed her course to the northwest reverting to the planned passage at approximately longitude $145^{\circ} \mathrm{E}$ (indicated by the red dot circle in Figure 3). It seems that sailing through a

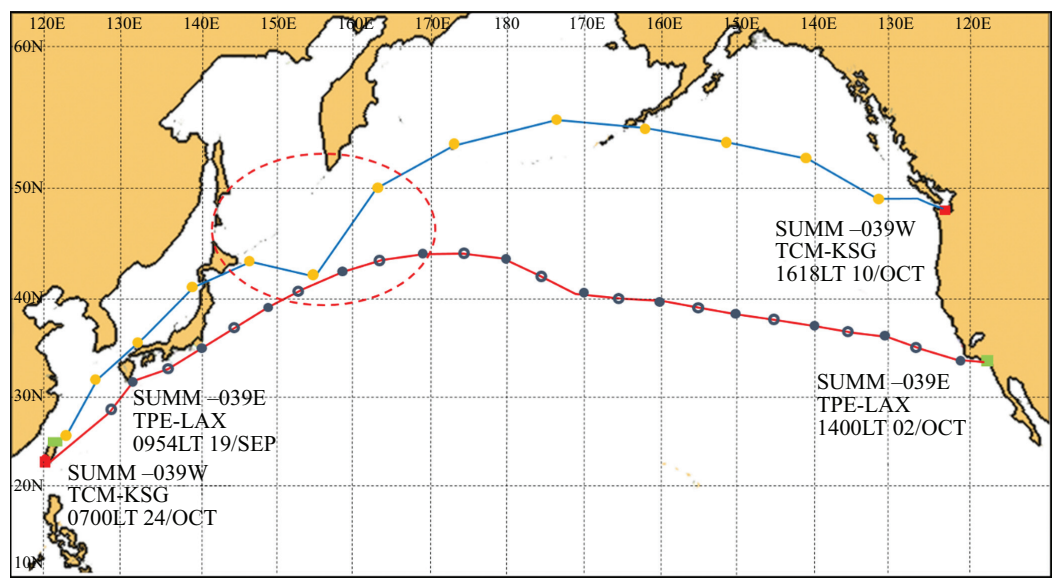

Figure 3. Sailing track of voyage W9 in the route of TCM-KSG 
MABR

6,3

new $\mathrm{GC}$ route to the destination port at the end of a severe weather condition would facilitate a shorter distance than to recover the former route.

\section{Discussions and suggestions}

\subsection{Discussions}

288 activity is both frequent and extensive, and its paths and moving speeds are complex. Extratropical cyclones mainly occur between $40^{\circ} \mathrm{N}$ and $30^{\circ} \mathrm{N}$. During the whole year, cyclone storms of the North Pacific primarily take place in January, initially moving to the northeast and then toward the Kuril Islands, the Aleutian Islands and the waters around the Gulf of Alaska (NGIA, 2018a). Due to frequent low-pressure activity in the North Pacific, the wind speed typically reaches Beaufort level 7-8. These strong winds approach the southwestern Aleutian Islands to the Kuril Islands and frequently damage ships and cargo. In winter, weather in the mid-high latitudes of the North Pacific Ocean is harsher than that in other seasons (Chen, 2002; Chen and Lee, 2008; OSCAR, 2021). When planning a route across the North Pacific Ocean, the route should be determined according to actual weather conditions and medium- and long-term weather forecasts and then with commercial considerations of operators and the ship's structure and performance. This study's findings contribute to different stakeholders in the maritime industry (e.g. seafarers, marine hull and machinery companies, P\&I clubs, ocean container carriers and freight forwarders) to clarify their responsibilities to achieve desired outcomes. The outstanding impacts are discussed as follows.

From a commercial perspective, ship operators often simply consider certain factors, such as sailing time, fuel consumption and cargo capacity of the ship, as well as schedule time based on the shortest distance of GC sailing; weather and ocean current changes are frequently ignored. These factors, however, have a significant impact on the performance of ships. When the captain adopts GC sailing to transit the ocean, he or she may encounter the strong influence of winds and currents, which will not only affect the safety of the seafarers, the ship and the cargo on board but also reduce operational efficiency. On the other hand, when the captain adopts the RL sailing plan, he or she will obtain the advantage of easy operation and the disadvantage of longer distance.

According to the results of the empirical analysis, ocean route planning should take numerous influencing factors into consideration. Indeed, an optimum route needs to comply with multiple criteria, which constitutes a non-linear programming problem. Route planning must assess relevant risks, weather, ocean currents and actual conditions during the whole passage and necessary deviations to maintain navigation safety (She and Lin, 2011; Tsou and Cheng, 2013; Wang and Jia, 1998; Wei and Zhou, 2012). It must also be careful not to increase the total cost of the voyage. Therefore, when the captain actually selects the route, he or she should comprehensively consider various factors, such as meteorological conditions, sea status and cargo load, at that time to select a relatively optimal route that is suitable for the current environment.

In terms of logistics, all stakeholders in the shipping industry want their business to function smoothly, e.g. it should be fast, accurate and stable on schedule and at a limited cost. Ship operators typically experience stress from various domains. In particular, the captain is in charge of the process of sailing and is responsible for the results achieved on behalf of the companies that have hired them. Consequently, it is critical that the captain considers the ship's characteristics and performance, the condition of the cargo onboard and meteorological trends, weather conditions and ocean conditions to enhance the performance of sailing. He or she is also responsible for the safety of seafarers, the ship and the cargo. The captain has to make decisions based on his or her knowledge, capability 
and any information that he or she can obtain before and during sailing when the ship transits the ocean (Chen, 2002; Chen and Lee, 2008). Traditionally, the captain checks all of the relevant charts, as well as certain publications, such as the Sailing Direction, the Port Entry Guide and the Pilot Chart, to collect sailing information to ensure sailing safety. Furthermore, the captain also receives weather forecasts, surface analyses and upper-level weather conditions by radio or satellite. Online modern marine weather forecast and weather routing services are also now widely available if the need arises.

In contrast, ship operator managers, insurance underwriters and charterers who remain on shore cannot monitor environment conditions in real time. However, they need detailed records to approve the ships' sailing performance if a claim occurs. The only credible official witness to events is the ships' logbook. Of course, many incidents are due to an "act of God", and sometimes the precise causes of incidents are unclear. Modern communication technology solves this problem. Specifically, the captain can remain online and receive real-time information concerning safe sailing over the Internet, including weather forecasts and route recommendations. This information can greatly assist ships to transit through the ocean safely and economically. It is also important to note that, according to the results of the analysis, sailing efficiency is random, which is in accordance with the findings of Brodl (2017). Indeed, distance, sailing time, and fuel consumption fluctuated markedly. Consequently, the ship captain should possess the professional capability to accurately assess route suggestions prior to accepting them.

Regarding the occurrence of claims in the shipping industry, claims may be due to schedule delays, damage to goods or damage to the ship. All of the stakeholders in the shipping industry want to determine details about performance and clarify the responsibility of the cause of the claim. The traditional official document, the logbook, is insufficient to achieve this. However, modern technology, e.g. weather routing services, acts as a third party, which provides weather forecasts, sailing route recommendations, records of real-time weather conditions and the sailing track (AWT, 2012). In fact, they provide such reliable evidence that all stakeholders rely on them (ASBA, 1981). Accordingly, most ship operators have established a policy that mandates that all ships' captains follow the recommendations of the weather routing service without deviation. It is the case that the captain does not have much time to study the trends of meteorological data or to discuss these data with weather routing service providers. Moreover, there are not sufficient data to enable verification of the optimal route prior to sailing. Since operators may lose claim judgments if they cannot provide objective evidence to show that they have performed competently in their sailing, weather routing services and online data services become vital.

Concerning the decision-maker, i.e. the captain of the ship, a dilemma arises when he or she questions recommendations from weather routing service providers. Indeed, he or she often faces multiple scenarios and various alternatives, and the results of the present trip may be unclear. Based on the empirical analysis in section 4, no common solutions or common performance of sailing were identified, even in cases in which the vessels followed the weather routing service suggestions. These results may also be the same as those obtained when the captain makes decisions based on his or her own professional capability and available information; however, such decisions would constitute weak legal evidence in claim disputes. In fact, they do confront many claims from ship operator managers, shippers, insurance underwriters and charterers. Even if the captain enjoys a disclaimer right according to the Hague Visby Rule (Qiu, 1997) or the Time Charter Party of the New York Produce Exchange (ASBA, 1981), he or she still receives many claims from various stakeholders regarding the results of sailing. These stresses on the captain make reaching decisions under time constraints extremely challenging. It is also important to note that the ship is sailing long distances across the ocean; thus, all decisions comprises various risks, irrespective of whether or not such decisions are recommended by the weather routing 
MABR

6,3

service. For these reasons, the easiest choice for captains is to follow the suggestions of the weather routing service when traversing the ocean and thus comply with the stakeholders' requirements, even if the results are not the best.

Generally, voyage planning is based on shortening the navigation time (ETA advance), using conditions that are favorable to speed as much as possible, such as favorable wind, favorable current, etc. and attempting to divert conditions that are not conducive to speed, such moving against the wind or against the sea current. The influence of the wind and waves on ship speed is non-linear. Moreover, under other conditions which influence ship speed, power output and fuel consumption cannot be expressed by simple algebra. Therefore, route planning should apply as many as favorable natural factors, and avoid as many unfavorable natural factors, as possible. Although the total distance might increase the sailing time, the increase in speed might compensate for the increase in range.

\subsection{Practical implementations and suggestions}

This study collected the sailing records of a container fleet that sailed throughout the North Pacific Ocean for performance analysis of the influence of using a weather routing service. The results will enable navigators to implement correct precautions in actual operations under different weather and sea conditions. Consequently, accurate estimations and judgments may be made and unfavorable weather conditions can be avoided to improve navigation safety and performance. Overall, our results can be beneficially utilized as a reference for reducing ship operation costs and for improving navigation planning.

The results of the current study are in accordance with extant literature demonstrating that using land-based meteorologists achieves no statistically significant improvement in fuel and time economy (Brodl, 2017). Therefore, vessels still face substantial uncertainty even when they adhere to the recommendations of weather routing services. Indeed, running time, speed and fuel consumption cannot be exactly predicted prior to implementation of the sailing plan (Brodl, 2017). Even if sailing safety is improved, vessels can still encounter many incidents, schedule delays, cargo damage or ship damage resultant from severe weather. The captain's choice of the optimal route is highly related to the safety of the ship and any potential financial loss of the shipping company's operation. The ship's operator company adopts the weather routing service while the ship is transiting the ocean. The captain often bears the responsibility for not relying on his or her own professional judgement, even when the ship operator does not mandate that the captain accepts the recommendations of the weather routing service. The captain shall, based on medium- and long-term weather forecasts, assess the impact of various routes, as well as weather and sea conditions, and consider the most suitable route among different routes to reduce sailing distance, fuel and time. He or she attempts to identify the shortest sailing time by using the safest route to avoid bad weather conditions as early as possible and make optimal use of natural factors, such as meteorological indicators, sea conditions and currents, that are conducive to improving the speed of navigation. In addition to nautical knowledge and skill, the captain still needs to possess sufficient meteorological knowledge that can assist him or her to predict weather conditions in the route ahead. At a minimum, he or she must possess the capability to judge and verify the recommendation route provided by the weather routing service in order to transit the ocean safely.

The ship operation manager should adopt the weather routing service to provide sufficient information related to weather forecasts to assist the captain to select an optimal alternative route. The primary aim of management must be to enhance the safety of sailing and not to control the sailing path or acquire credible evidence to defend against legal claims. Furthermore, management should also establish a viable plan to enhance the weather forecast capability of navigators by supporting them to identify alternatives to the recommendations of the weather routing service. 
Based on the results of the empirical analysis, shippers and charterers should be aware that vessels sailing across the ocean at long distances are doing so under many influential factors, e.g. meteorological factors, weather conditions, ocean conditions, characteristics of the ship and the cargo carried onboard. Moreover, the ship's speed, sailing time and fuel consumption are usually varied. As a consequence, a large margin of error should be maintained regarding these aspects. For example, if a schedule is arranged too strictly, a vessel may arrive later than intended. It is suggested that they monitor the path of sailing together with the weather routing service continually to assess their plan to achieve better performance and not just monitor whether or not watch the captain is following the recommendations of the weather routing service.

According to the empirical analysis, insurance underwriters should be cognizant of the fact that sailing performance is neither certain nor regular. Indeed, even if the vessel follows the recommendation route provided by the weather routing service, it can still face great risks and uncertainty. Furthermore, when damage occurs during sailing, its cause is generally beyond the captain's control or it constitutes an "act of God". Therefore, when insured parties submit claims, the underwriter should fulfill those claims based on mutual trust. When the captain's capability is not censured or operation defects are not unduly emphasized, it is much more likely that he or she will do his or her best with confidence to make good decisions when encountering all types of risks.

Although this study has made a crucial contribution to fleets traveling across the North Pacific Ocean, only ten sailing records of eastbound and westbound routes were employed in this study. In order to obtain more detailed and comprehensive results, it is suggested to collect additional sailing records that adopted weather routing services' recommendations to analyze sailing performance in future research.

\section{References}

ASBA (Association of Ship Brokers and Agents) (1981), "Time charter-New York produce exchange form", available at: https://charterpartyeditor.co/images/Forms/ASBATIME_CPE.pdf.

AWT (Applied Weather Technology) (2012), "Weather route service training material”, available at: http://www.awtworldwide.com.

Brodl, L. (2017), Evaluating Weather Routing, Master's Thesis of Lund University, Swedish.

Chang, H.K. (2012), "Basic theory of wave", available at: http:/ocean.cv.nctu.edu.tw/NRCEST/ teaching/wavedynamic/chap4_5_6.pdf.

Chen, M.M.L. and Lee, S.C. (2008), Heavy Weather Avoidance and Route Design-Concepts and Applications of 500MB Chart, Paradise Cay Publications, Arcata, CA.

Chen, M.L. (2002), The Technology of 500Mb High Level Weather Chart in Navigation and Ocean Route Design, Sense Production, Hong Kong.

Flecks, J. (2009), Study Green Shipping, HVB Global Shipping, Hamburg, pp. 4-5.

Lu, C.M. (2014), Analysis of Meteorological Route and Navigational Safety: The North Pacific Ocean Route as Sample, Master Thesis of National Kaohsiung Marine University, R.O.C.

National Geospatial Intelligence Agency (NGIA) (2018a), The American Practical Navigator-An Epitome of Navigation, 2017 Bicentennial Ed., Springfield, Virginia.

National Geospatial Intelligence Agency (NGIA) (2018b), "Maritime safety information: Atlas of Pilot charts North Pacific ocean", available at: http://msi.nga.mil/NGAPortal/MSI.portal?_nfpb=true\&_ st $=\& \_p a g e L a b e l=m s i \_p u b \_d e t a i 1 \& C C D \_i t e m I D=108 \&$ pubConstant $=A P C o n 01 / 0 c t . / 2020$.

National Imagery and Mapping Agency (NIMA) (2002), The American Practical Navigator-An Epitome of Navigation, 2002 Bicentennial Ed, Bethesda, Maryland.

OSCAR (Ocean Surface Currents Analyses-Real time) (2021), available at: http://www.oscar.noaa.gov/. 
MABR 6,3

Qiu, Z.F. (1997), Maritime Claims. 2ed, Evergreen International, Taipei.

She, L.T. and Lin, B. (2011), "Effects of weather routing on ship sailing time in the North Pacific Ocean”, Journal of Taiwan Maritime Safety and Security Studies, Vol. 2 No. 5, pp. 1-16.

Su, D.T. (1999), Research on Fluid Dynamic Characteristics of Special Marine Operation Ships, The Master Thesis of Zhongzheng Institute of Technology, R.O.C.

The United Nations Conference on Trade and Development (UNCTAD) (2020), "The review of maritime transport 2020", available at: https://unctad.org/en/PublicationsLibrary/rmt2020_ en.pdf.

Tsou, M.C. and Cheng, H.C. (2013), "An ant colony algorithm for efficient ship routing”, Polish Maritime Research, Vol. 3 No. 79, pp. 28-38.

Wang, F. and Jia, C. (1998), "The study on the optimal ship routing, in Chinese", Journal of Dalian Maritime University, Vol. 24 No. 2, pp. 61-64.

Wei, S. and Zhou, P. (2012), "Development of a 3D dynamic programming method for weather routing", International Journal on Marine Navigation and Safety of Sea Transportation, Vol. 6 No. 1, pp. 79-83.

Yin, R.K. (2014), Case Study Research: Design and Methods, 5th ed., Sage, Thousand Oaks, CA.

Zainal, Z. (2007), "Case study as a research method”, Jurnal Kemanusiaan Bil, Vol. 5 No. 1, pp. 1-6.

\section{Further reading}

The Work Plan of the Artificial Intelligence Vessel Development (2019-2021), available at: www.miit. gov.cn/n1146295/n1652858/n1652930/. . ./6567973.pdf.

Tsou, M.C. (2010), "Integration of a geographic information system and evolutionary computation for automatic routing in coastal navigation", The Journal of Navigation, Vol. 63, pp. 323-341.

\section{Corresponding author}

Chaur-Luh Tsai can be contacted at: chaurluh@nkust.edu.tw

For instructions on how to order reprints of this article, please visit our website:

www.emeraldgrouppublishing.com/licensing/reprints.htm

Or contact us for further details: permissions@emeraldinsight.com 